\title{
Commentary
}

\section{Journalism at the Periphery}

\author{
Edson C. Tandoc Jr. \\ Wee Kim Wee School of Communication and Information, Nanyang Technological University, 637718 Singapore, Singapore; \\ E-Mail: edson@ntu.edu.sg
}

Submitted: 10 November 2019 | Accepted: 18 November 2019 | Published: 17 December 2019

\begin{abstract}
The increasing influence of actors who might not fit into traditional definitions of a journalist but are taking part in processes that produce journalism has attracted scholarly attention. They have been called interlopers, strangers, new entrants, peripheral, and emergent actors, among others. As journalism scholars grapple with how to refer to these actors, it is important to reflect on the assumptions that underlie emerging labels. These include: 1) what journalistic tasks are involved; 2) how and why these journalistic tasks are performed; 3) who is making the definition; and 4) where and when these actors are located. However, journalism being the centre of our investigation should not automatically assume that it is at the centre of social life. So, it might also be that for the technological field, journalism is at the periphery; that for these technology-oriented actors whose influence across fields is increasing, journalists and what they do are at the periphery. For a field that supposedly plays an important role in public life, this has important implications.
\end{abstract}

\section{Keywords}

boundary work; Bourdieu; interlopers; journalism; peripheral actors; social media

\section{Issue}

This commentary is part of the issue "Peripheral Actors in Journalism: Agents of Change in Journalism Culture and Practice" edited by Avery E. Holton (University of Utah, USA), Valerie Belair-Gagnon (University of Minnesota-Twin Cities, USA), and Oscar Westlund (Oslo Metropolitan University, Norway / Volda University College, Norway / University of Gothenburg, Sweden).

(C) 2019 by the author; licensee Cogitatio (Lisbon, Portugal). This article is licensed under a Creative Commons Attribution 4.0 International License (CC BY).

\section{Introduction}

This thematic issue offers a timely and important exploration of the rise of actors who might not fit into traditional definitions of a journalist but are taking part in processes that produce journalism. These actors-such as data scientists making sense of web analytics data (BelairGagnon \& Holton, 2018), technologists who provide automation services to newsrooms ( $\mathrm{Wu}$, Tandoc, \& Salmon, 2019), bloggers and blogs that produce a variety of media content that includes journalism (Eldridge, 2018b), as well as those producing user-generated news (Tong, 2015) - have been referred to in different ways.

Eldridge (2018b, p. 858) wrote about "interloper media," which referred to "a subset of digitally native media and journalistic actors who originate from outside the boundaries of the traditional journalistic field, but whose work nevertheless reflects the socio-informative functions, identities, and roles of journalism." Holton and
Belair-Gagnon (2018, p. 72) referred to "strangers" in journalism, or those who "did not belong in journalism from the beginning, and are importing qualities to it that do not originally stem from the journalistic profession." This thematic issue itself focuses on "peripheral actors," defined as "those individuals or organizations not traditionally defined as or aligned with journalism" (Holton \& Belair-Gagnon, 2018).

The introduction of these terms into journalism studies lexicon to describe non-traditional actors in journalism is important. First, these terms help facilitate a systematic study of the actors they attempt to label as well as these actors' practices and their impact on journalism. Second, the terms we use to label these actors can shape our understanding and expectations of how these actors should behave, which can affect how we study them and their practices. It is, therefore, also important that we scrutinize and reflect on the assumptions that underlie these different terms. 


\section{Defining Non-Traditional Actors}

The term "stranger" is not a strange word in journalism studies. It has been used to refer to news sources (Gans, 2007) and audiences (Carey, 2007; Venables, 2003), which are both considered to be external to, but influencing, journalism. Nor is the term "peripheral" at the periphery of journalism studies. However, the studies that have used notions of the periphery in the field of journalism referred to less dominant types of journalism, such as free daily newspapers (Lamour, 2019), non-metropolitan news outlets (Hutchison \& O'Donnell, 2011), and entertainment journalism (Loosen, 2015), among others.

These terms, along with newer terms such as "interloper" and "emergent" (Eldridge, 2018a), among others, are now used to refer to actors doing journalism but are not (yet) considered as journalists. Embedded within these labels are particular assumptions, referring to: 1) what journalistic tasks are involved; 2 ) how and why these journalistic tasks are performed; 3 ) who is making the definition; and 4) where and when these actors are located (see Table 1).

\subsection{Journalistic Acts}

The proposed definitions of these terms refer to a range of acts supposedly related to journalism. For example, in categorizing interlopers as either explicit or implicit, Holton and Belair-Gagnon (2018, p. 73) referred to actors who "work on the periphery of the profession while directly contributing content or products to the creation and distribution of news." Such delineation of the term based on acts and the outputs of such acts provides, at most, a tentative definition, one that is challenging to operationalize, as the set of processes that directly contribute to news production is also expanding. Social media, for example, brought about new routines, such as promoting one's work. These are tasks that were, in the past, not possible and therefore not required to produce news. These new tasks that many news organizations now consider to directly contribute to news production also require new editorial positions needing new skillsets that were not part of traditional journalistic training, with big news outlets designating social media managers or audience engagement editors to work alongside news editors (Ferrer-Conill \& Tandoc, 2018). In classifying these new job designations as editor-level functions, some news outlets seem to clearly recognize the tasks involved as directly related to journalism. Thus, whom journalism scholarship might consider as peripheral actors by virtue of the acts they perform might be occupying central roles in some newsrooms.

\subsection{Norms and Roles}

These terms and their definitions also refer to norms and roles that guide and motivate the performance of journalism-related acts. Journalistic rules and roles are important. How journalists view their roles is assumed to shape their performance and, consequently, their outputs (Donsbach, 2008; Shoemaker \& Reese, 2014). In defining interloper media, Eldridge (2018b, p. 858) referred to a kind of work that "reflects the socio-informative functions, identities, and roles of journalism." But Holton and Belair-Gagnon (2018, p. 73) also said "technology-oriented media interlopers" might bring "new practices and norms in journalism." Therefore, while these definitions refer to adherence to a set of norms and roles, what these norms and roles actually are remain constantly negotiated. On one hand, new actors are expected to play by the rules of journalism. But on the other hand, they also bring with them rules from their previous fields.

Non-traditional actors entering the field of journalism can also be considered as "new entrants" to the field (Bourdieu, 1993). As new entrants, these actors might contribute to either the preservation or the transformation of the field, for while they might play by the prevailing rules in order to gain legitimacy in the field, they also bring with them the norms and roles that originate from their own fields. For example, Wu et al. $(2019$, p. 15) argued that the influence of the technological field, which focuses heavily on markets, audiences, and data, "is al-

Table 1. Components of key terms.

\begin{tabular}{ll}
\hline What & What do these non-traditional actors do in relation to journalism? \\
\hline How & How are they performing these tasks? \\
\hline Why & What roles do they seek to (or currently) fulfill? \\
\hline Who & $\begin{array}{l}\text { How does the ongoing negotiation of what it means to be a journalist reflect the changing power dynamics } \\
\text { among traditional and non-traditional actors in journalism, and in what ways do journalism researchers } \\
\text { normalize, if not perpetuate, such power dynamics in how they design their studies? }\end{array}$ \\
\hline \begin{tabular}{ll} 
Where & $\begin{array}{l}\text { What do we really mean when we dichotomize between the centre and the periphery in journalism, when } \\
\text { boundaries of the profession are ever changing? }\end{array}$ \\
\hline When & How do we shift from considering what is not journalism to when does something become journalism?
\end{tabular} \\
\hline
\end{tabular}

Note: Scrutinizing the assumptions embedded in how we label non-traditional actors now playing significant roles in journalistic processes will help in drafting a nuanced research agenda, one that interrogates each of the assumptions embedded in these labels. 
ready evident in journalism's shift towards data-centric and short, easy-to-digest content that cater to audience preferences."

\subsection{Definitional Control}

These terms also interrogate the ones making the definitions. Holton and Belair-Gagnon (2018) referred to nontraditional actors who may or may not be welcomed by journalists, and who may or may not define themselves as journalists. Eldridge (2018b, p. 876) also referred to how non-traditional actors "portray their own journalistic identities and intentions" as well as how they are "perceived by the publics being addressed." These definitions represent an ongoing negotiation between traditional and non-traditional actors in defining and locating the latter's position in journalism. This is consistent with the assumptions of boundary work in journalism (Carlson, 2015). But Eldridge's (2018b) definition also brings into the mix the role of audiences in this ongoing negotiation of journalistic identities, consistent with previous work that investigated how news audiences are taking part in journalistic boundary work (e.g., Jenkins \& Tandoc, 2017). The power to define the location of these non-traditional actors is still being contested, but what is rarely highlighted is the role of journalism scholars in this discursive contest.

\subsection{Location}

Finally, these labels tend to locate this group of actors either outside or at the edges of journalism. Interloper actors are said to originate from "outside the boundaries of the traditional journalistic field" (Eldridge, 2018b, p. 858), while journalism strangers "did not belong in journalism from the beginning" (Holton \& Belair-Gagnon, 2018 , p. 72). Thus, location is not just spatial but also temporal. Existing outside journalism at the beginning does not preclude being within journalism's boundaries at some point in time.

But what constitutes the boundaries of journalism? Where is journalism's core? A common approach in tackling these questions is considering traditional journalistic standards as forming part of the core, and then using these traditional standards that have dominated journalism to evaluate non-traditional actors. We see new developments from the lens of history; we examine new data using frameworks grounded in dominant theoretical approaches and previous studies. For example, the use of big data in journalism has been examined based on traditional news values and routines (e.g., Dick, 2014; Tandoc \& Oh, 2017). And yet, while discourse about boundary work and peripheral actors assumes a journalistic centre, the literature remains unclear on how that centre looks like and what it constitutes. Studies that sought to identify journalism's boundaries, including my own work, relied on journalism studies literature that is heavily skewed toward hard news, arguably at the expense of other types of journalism, such as lifestyle journalism (Hanusch, 2012). What audiences now consider as news and what they consider as responsible journalism are also changing; documenting and unpacking these might serve journalism studies a better purpose than reifying standards that scholarship has designated to be dominant.

Scrutinizing the assumptions embedded in how journalism studies label non-traditional actors now playing significant roles in journalistic processes will help in drafting a nuanced research agenda, one that interrogates each of the assumptions embedded in these labels. What do these non-traditional actors do in relation to journalism? How are they performing these tasks and what roles do they play (and how does that role compare with the one they originally sought to play)? How does the ongoing negotiation of what it means to be a journalist reflect the changing power dynamics among traditional and non-traditional actors in journalism, and in what ways do journalism researchers normalize, if not perpetuate, such power dynamics in how we design our studies and choose the labels we use? Finally, what do we really mean when we dichotomize between the centre and the periphery in journalism, when boundaries of the profession are ever changing? Who decides where the centre is and where the periphery is?

\section{Journalism at the Periphery}

A general assumption that underlies many of these agendas and dilemmas is the consideration of journalism as occupying the centre. This is, of course, a logical consequence of our research focus on journalism studies. However, journalism being the centre of our investigation should not automatically assume that it is at the centre of social life. Schudson $(1997,463)$, for example, argued that "the importance of journalism, relative to other factors in human affairs, is to be demonstrated, not assumed."

When Bourdieu (1998) applied the framework of field theory to journalism, he focused on television's impact on politics in France. Bourdieu (1998, p. 2) observed that journalism has presented to the public a "particular vision of the political field" that was consistent with what journalism considered as newsworthy more than with the routinized and usually unappealing processes of the political field. During its heyday, journalism extended its influence to the political field and to other fields (Bourdieu, 2005), occupying what others might argue as a "central position" in social life. News organizations became big businesses and amassed political and social capital.

Now, traditional news organizations are losing audiences and, consequently, advertising revenues. News media credibility is decreasing as fake news becomes more convincing and influential (Wahutu, 2019). A few studies have examined how some people intentionally avoid the news (e.g., Song, 2017; van den Bulck, 2006). 
Faced with eroding economic and cultural capital, many agents in the journalistic field turn to external actors for help. News outlets welcome, if not seek, non-traditional actors, such as data scientists, into their newsrooms. In doing so, these agents expose the journalistic field to external influence, in this case the influence of the technological field, which operates with a different set of rules. This can be seen as journalism's attempt to regain its once central position in social life, now lost to the technological field, whose agents dominate societies in accumulating both economic and cultural capital, expanding their field's influence along with its set of rules across different facets of social life, from interpersonal communication to healthcare, from community-formation to manufacturing. For example, social media platforms and search engines get the lion's share of audience attention and advertising online as media consumption now increasingly occurs on social media platforms and messaging apps. This has led the news media to play by the rules of the technological field, such as by tweaking headline-writing conventions to suit the purposes of search engine optimization (Dick, 2011) and by producing more native videos when Facebook decided to tweak its newsfeed algorithm to prioritize native videos (Tandoc \& Maitra, 2018). Newsworthy content also now routinely flows from companies that began as technology startups (Kung, 2015; Prasad, 2019). Those who seek to influence public opinion no longer relies solely on news media coverage-they can now potentially command public and media attention with just one tweet.

Many studies in journalism have focused on examining social media platforms using the lens of traditional journalism, but rarely do scholars interrogate journalism through the lens of the technological field. From January 2013 to November 2019, Digital Journalism, one of the top journals in journalism studies, published 499 articles containing the keyword "journalist," while it published 42 articles studying automation in journalism containing the keyword "robot." The International Journal of Robotics Research published in the same time period 629 articles containing the keyword "robot," while it published only two articles containing the keyword "journalist." This reflects a clear imbalance between journalism scholars' focus on automation in journalism and automation scholars' focus on journalism in automation. While automation in journalism is attracting attention from an increasing number of journalism scholars, automation scholars rarely investigate how journalism figures in automation.

By operating under the assumption that journalism is at the periphery of social life, we can examine how it attempts to regain its position at the centre by playing by the rules of other fields. This requires a refocusing of our conceptual lenses and an increase in interdisciplinary work. It also means that while it is important to understand the perspective of journalists about journalism, it is equally important to understand how non-journalists perceive journalism. For example, stud- ies have conducted observations of and interviews with technology professionals and managers at web analytics and automation companies to understand journalism's place in the technological field (e.g., Belair-Gagnon \& Holton, 2018; Petre, 2018; Wu et al., 2019). These studies have shown that many non-traditional actors are reluctant in labelling themselves as journalists, even if they acknowledge that the work they do is directly related to journalism. Where is this reluctance, if not resistance, coming from? What does it mean to willingly engage in journalism and not consider oneself as a journalist? These technologies now attracting the attention of journalism practitioners and researchers were not developed specifically for journalism (Moyo, Mare, \& Matsilele, 2019). So, it might also be that for the technological field, journalism is at the periphery; that for these technology-oriented actors whose influence across fields is increasing, journalists and what they do are at the periphery. For a field that supposedly plays an important role in public life, this has important implications.

\section{Acknowledgments}

The author wishes to thank the editors and reviewers for their guidance in writing this commentary. The author also wishes to thank Steen Steensen, Joy Jenkins, Sonny Rosenthal, and Ryan Thomas for their valuable comments and suggestions.

\section{Conflict of Interests}

The author declares no conflict of interests.

\section{References}

Belair-Gagnon, V., \& Holton, A. E. (2018). Boundary work, interloper media, and analytics in newsrooms. Digital Journalism, 6(4), 492-508. https://doi.org/10.1080/ 21670811.2018.1445001

Bourdieu, P. (1993). The field of cultural production. New York, NY: Columbia University Press.

Bourdieu, P. (1998). On television. New York, NY: The New Press.

Bourdieu, P. (2005). The political field, the social science field and the journalistic field. In R. Benson \& E. Neveu (Eds.), Bourdieu and the journalistic field (pp. 29-47). Malden, MA: Polity Press.

Carey, J. W. (2007). A short history of journalism for journalists: A proposal and essay. Harvard International Journal of Press/Politics, 12(1), 3-16. https://doi.org/ 10.1177/1081180X06297603

Carlson, M. (2015). Metajournalistic discourse and the meanings of journalism: Definitional control, boundary work, and legitimation. Communication Theory, 26(4), 349-368. https://doi.org/10.1111/comt. 12088

Dick, M. (2011). Search engine optimisation in UK news production. Journalism Practice, 5(4), 462-477. 
https://doi.org/10.1080/17512786.2010.551020

Dick, M. (2014). Interactive infographics and news values. Digital Journalism, 2(4), 490-506. https://doi.org/10. 1080/21670811.2013.841368

Donsbach, W. (2008). Journalists' role perceptions." In Donsbach (Ed.), The international encyclopedia of communication (2605-2610). Malden, MA: WileyBlackwell.

Eldridge, S. A., II. (2018a). Repairing a fractured field: Dynamics of collaboration, normalization and appropriation at intersections of newswork. Journal of Applied Journalism \& Media Studies, 7(3), 541-559. https://doi.org/10.1386/ajms.7.3.541_1

Eldridge, S. A., II. (2018b). "Thank god for Deadspin": Interlopers, metajournalistic commentary, and fake news through the lens of "journalistic realization." New Media \& Society, 21(4), 856-878. https://doi. org/10.1177/1461444818809461

Ferrer-Conill, R., \& Tandoc, E. C., Jr. (2018). The audienceoriented editor: Making sense of the audience in the newsroom. Digital Journalism, 6(4), 436-453. https://doi.org/10.1080/21670811.2018.1440972

Gans, H. J. (2007). Everyday news, newsworkers, and professional journalism. Political Communication, 24(2), 161-166. https://doi.org/10.1080/ 10584600701312878

Hanusch, F. (2012). Broadening the focus: The case for lifestyle journalism as a field of scholarly inquiry. Journalism Practice, 6(1), 2-11. https://doi.org/10.1080/ 17512786.2011.622895

Holton, A., \& Belair-Gagnon, V. (2018). Strangers to the game? Interlopers, intralopers, and shifting news production. Media and Communication, 6(4), 70-78. https://doi.org/10.17645/mac.v6i4.1490

Hutchison, D., \& O’Donnell, H. (Eds.). (2011). Centres and peripheries: Metropolitan and non-metropolitan journalism in the 21st century. Newcastle upon Tyne: Cambridge Scholars.

Jenkins, J., \& Tandoc, E. C., Jr. (2017). The power of the cover: Symbolic contests around the Boston bombing suspect's Rolling Stone cover. Journalism, 18(3), 281-297. https://doi.org/10.1177/ 1464884915614240

Kung, L. (2015). Innovators in digital news. New York, NY: I.B. Tauris.

Lamour, C. (2019). The legitimate peripheral position of a central medium. Journalism Studies, 20(8), 11671183. https://doi.org/10.1080/1461670X. 2018.1496026

Loosen, W. (2015). The notion of the "blurring boundaries": Journalism as a (de-)differentiated phenomenon. Digital Journalism, 3(1), 68-84. https://doi.org/10.1080/21670811.2014.928000

Moyo, D., Mare, A., \& Matsilele, T. (2019). Analyticsdriven journalism? Editorial metrics and the reconfiguration of online news production prac- tices in African newsrooms. Digital Journalism, 7(4), 490-506. https://doi.org/10.1080/21670811. 2018.1533788

Petre, C. (2018). Engineering consent: How the design and marketing of newsroom analytics tools rationalize journalists' labor. Digital Journalism, 6(4), 509-527. https://doi.org/10.1080/21670811. 2018.1444998

Prasad, R. (2019). Digital disruption? Journalism startups in India. Journalism. Advance online publication. https://doi.org/10.1177/1464884919852446

Schudson, M. (1997). Toward a troubleshooting manual for journalism history. Journalism \& Mass Communication Quarterly, 74(3), 463-476. https://doi.org/ $10.1177 / 107769909707400302$

Shoemaker, P. J., \& Reese, S. D. (2014). Mediating the message in the 21st century: A media sociology perspective. New York, NY: Routeledge.

Song, H. (2017). Why do people (sometimes) become selective about news? The role of emotions and partisan differences in selective approach and avoidance. Mass Communication and Society, 20(1), 47-67. https://doi.org/10.1080/15205436.2016.1187755

Tandoc, E. C., Jr., \& Maitra, J. (2018). News organizations' use of native videos on Facebook: Tweaking the journalistic field one algorithm change at a time. New Media \& Society, 20(5), 1679-1696. https://doi.org/ $10.1177 / 1461444817702398$

Tandoc, E. C., Jr., \& Oh, S.-K. (2017). Small departures, big continuities? Norms, values, and routines in The Guardian's big data journalism. Journalism Studies, 18(8), 997-1015. https://doi.org/10.1080/ 1461670X.2015.1104260

Tong, J. (2015). Chinese journalists' views of usergenerated content producers and journalism: A case study of the boundary work of journalism. Asian Journal of Communication, 25(6), 600-616. https://doi. org/10.1080/01292986.2015.1019526

van den Bulck, J. (2006). Television news avoidance: Exploratory results from a one-year follow-up study. Journal of Broadcasting \& Electronic Media, 50(2), 231-252. https://doi.org/10.1207/ s15506878jobem5002_4

Venables, D. (2003). Strangers in the newsroom: Public journalism and news selection processes on New Zealand daily newspapers. Australian Journalism Review, 25(1), 197-214.

Wahutu, J. S. (2019). Fake news and journalistic "rules of the game." African Journalism Studies. Advance online publication. https://doi.org/10.1080/23743670. 2019.1628794

Wu, S., Tandoc, E. C., Jr., \& Salmon, C. (2019). When journalism and automation intersect: Assessing the influence of the technological field on contemporary newsrooms. Journalism Practice, 13(10), 1238-1254. https://doi.org/10.1080/17512786.2019.1585198 


\section{About the Author}

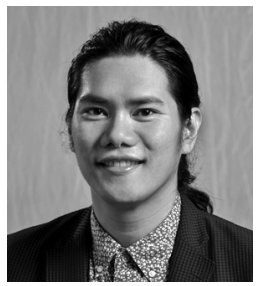

Edson C. Tandoc Jr. (PhD, University of Missouri) is an Associate Professor at the Wee Kim Wee School of Communication and Information at Nanyang Technological University in Singapore. His research focuses on the sociology of message construction in the context of digital journalism. He has conducted studies on the construction of news and social media messages. His studies about influences on journalists have focused on the impact of journalistic roles, new technologies, and audience feedback on the various stages of the news gatekeeping process. For example, he has done some work on how journalists use web analytics in their news work and with what effects. This stream of research has led him to study journalism from the perspective of news consumers as well, investigating how readers make sense of critical incidents in journalism and take part in reconsidering journalistic norms and how changing news consumption patterns facilitate the spread of fake news. 